\title{
Difference in Press Angle to the Quality of Briquettes
}

\author{
Nofriady Handra*, Hafni Hafni and Hendriwan Fahmi \\ Institut Teknologi Padang, Mechanical Engineering Department, Padang, West Sumatra Indonesia
}

\begin{abstract}
The development of biomass has been an important issue for the past several decades and would remain to be attractive in the future due to its clean, renewable, and carbon-neutral properties. The use of Empty Fruit Bunch (EFB) has been the condition of fibre and conditions of EFB is still fresh. The fiber used has been cut to size between $\pm 0.5 \mathrm{~mm}$ to $5 \mathrm{~mm}$. The purpose of this research is to determine the effect of difference press angle to the quality of briquette. Effect of the angle of the mold on the duration of combustion shows the difference in the time value that is not significant between the angles $65^{\circ}, 55^{\circ}$ and $45^{\circ}$. The rotation of the screw shaft slows down at an angle of $45^{\circ}$ with a round of $84.5 \mathrm{rpm}$, while the rotation of the shaft has increased in rotation at $65^{\circ}$ angle with rotation of $90.6 \mathrm{rpm}$. Differences in the cone angle affect the value of the burning time of the specimen and the rotation of the screw shaft so that it affects the engine performance.
\end{abstract}

\section{Introduction}

Biomass energy has attracted as one of the potential alternatives as it is an ideal renewable energy source with several advantages like lower sulfur, CO neutral emission, and abundant availability generally in the form of waste from agriculture as well as other 2 sources. Bioenergy derived from biomass is a promising, inexhaustible, sustainable source and can help in minimizing the rising environmental, economic, and technological issues related to depleting fossil fuels.

Increasing environmental and energy dependency concerns have been the motivation for the increased use of bio-energy as a substitute for fossil energy. The development of biomass has been an important issue for the past several decades and would remain to be attractive in the future due to its clean, renewable, and carbon-neutral properties [1].

Energy and fuels are the important links in the civilization and human development. The issues associated with the use of the fossil fuel, demand and supply gap, ever increasing prices, global warming and other environmental issues made the world to think for alternate sources of energy like solar, wind, ocean and biomass which are the only indigenous renewable energy sources capable of replacing large amount of solid, liquid and gaseous fossil fuel [2]

Palm oil is one of the commodities traded agricultural products, both for domestic and export industries. Following the processing of palm oil, eventually leaving palm Empty Fruit Bunch (EFB), which generally are not processed again by the oil industry in the processing of palm oil. Remaining empty bunches this poses a problem for venues and transportation disposal resulting in additional production costs for the processor. EFB in exile usually burned, it also creates problems for the environmental damage that air pollution and odor [3].

One of the optimistic technologies for alleviating these problems is briquetting, which has been studied by many researchers. The technology may be defined as a densification process for improving the handling characteristics of raw material and enhancing the volumetric calorific value of the biomass. Considerable amount of research on briquetting technology has been conducted [4].

Based on several problems in background discussions and see the potential of environmentalists, EFB waste must be managed wisely in order to demand the use of renewable alternative energy biomass, biomass utilization technology and produce environmentally friendly heat energy. The development of agricultural wastes for solid fuels is also triggered by the current condition, where fossil fuels which have been a mainstay for households or industries have increased prices [5]. Given the fact, the waste is very potential to be a solid fuel that is relatively cheaper and is expected to minimize environmental problems during the resulting waste handling. Utilization of EFB as a source of energy in the form of briquettes, in addition to providing financial benefits, also helps in environmental conservation. EFB can be made charcoal with a relatively simple process. For purposes of utilization as charcoal, EFB needs to be further processed into charcoal briquettes to increase their density and provide a regular shape by applying appropriate pressure to the briquette mold angle [5][6].

One of alternative solution is to treat the agricultural waste into briquettes, a solid alternative fuel, cheap and meet the technical specifications, namely by

Corresponding author: nof.hand11@gmail.com 
the pressure on the mold. The purpose of this study is to determine the effect of different press briquette angle, so as to produce optimal briquette output in terms of physical properties.

\section{Materials and Methods}

\subsection{Material}

The results of the study will produce bio-briquette from EFB waste. EFB wastes are obtained from the oil palm industry located in TAL Ltd - Riau Province. Waste obtained is after going through the process of enumeration with the engine so that the palm fiber are obtained that are rougher and still fresh. EFB used first to be smoothing up to $\pm 5 \mathrm{~mm}$, draining to moisture content $\pm 0.8 \%$. The EFB waste as shown in Fig. 1

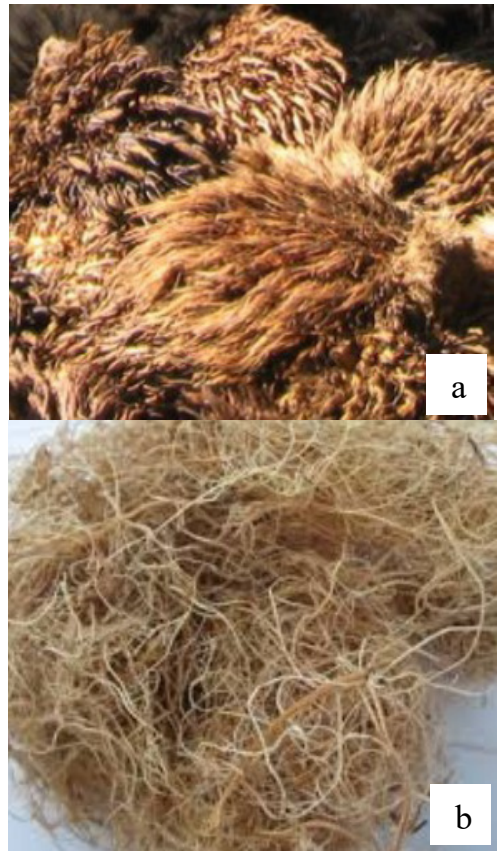

Fig. 1. Empty Fruit Bunch waste (a). EFB fibre (b)

\subsection{Screw press machine}

The research process consists of preparing the main ingredients in the form of EFB, then drying to reduce the water content in $\mathrm{EFB}$, and further refinement of the size up to $\pm 1 \mathrm{~mm}$ until $5 \mathrm{~mm}$ to facilitate the mold process. The briquette printing tool is categorized as manual and automatic mold, with different advantages and disadvantages of each. Manual tools are usually used with the help of hydraulic with piston system, where to insert material, press and remove the whole material done manually. Pressing briquettes requires a drive that will be adjusted to capacity of the tool used, the system can be screw, piston, hydraulic and other systems, the operator only needs to insert the material to be pressed into the tool, the tool will press until briquettes out through the mold with the shape and size that has been determined. System screw can be used for large capacity because it works continuously but requires a lot of power for its operation.

Fig. 2 is a screw press briquette machine used to mold briquettes with a diameter of $4 \mathrm{~mm}$. The mold angle varies with three variations of $65^{\circ}, 55^{\circ}$, and $45^{\circ}$ in order to obtain a briquette that meets the qualifications according to SNI standard 01-6235-2000 with different mold angles.

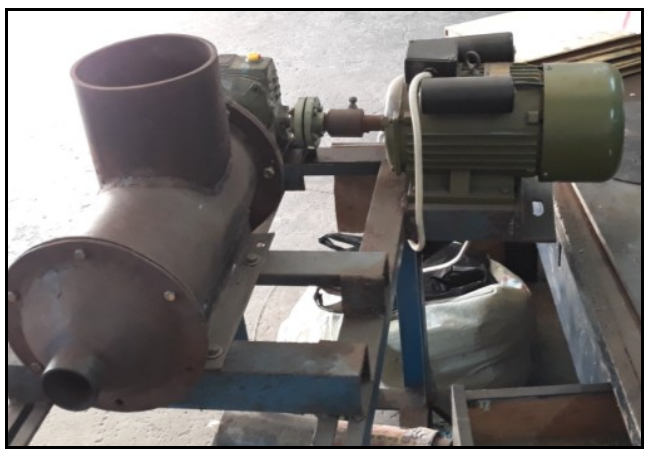

Fig. 2. Briquette machine of screw press

Extrusion is a process that combines several processes including mixing, destruction, molding and forming. The extruder consists of a screw (pressurized thread) which presses the raw material into a semi-solid material. The material is pressed out through a limited hole (mold) on the tip of the thread, if the raw material is heated. The main characteristic of the extrusion process is its continuous nature. The extruder is operated in a dynamic equilibrium condition, that is, the input equals the output, the incoming material is equivalent to the product. The extrusion process uses high mechanical energy and thermal energy with high pressure, this will result in the materials in the form of powders and grains changed into more fluid. Therefore, material characteristics such as surface friction, hardness, particle density are important to note.

\subsection{Mold of briquettes}

Cone-shaped plate is made so that the process of emphasis on the angle of the outer to form a briquette. Occurrence of emphasis resulted from the rotation of the screw shaft into the conical corner mold space. The cone dimensions are $D_{1}=133.4 \mathrm{~mm}$ and $d_{2}=43.4 \mathrm{~mm}$. Variation of a briquette mold angle used in this study as shown in Fig. 3.

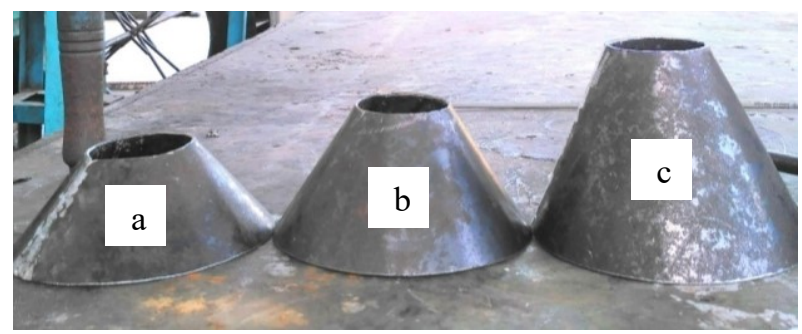

Fig. 3. Variation of briquette mold angle (a) $45^{\circ}$ (b) $55^{\circ}$ and $(\mathrm{c}) 65^{\circ}$ 


\section{Result and Discussion}

The briquetting process is the process of converting low-density biomass into solid fuel in the form of briquettes with concentrated energy and high density. The preparation of a biomass solid fuel can be said to be an identification process aimed at improving the biomass fuel characteristics. The essential properties of briquettes that affect fuel quality are their physical properties and chemical properties. Physical properties include density characteristics, briquette size, water content, calorific value, and volume unity energy. Briquetting techniques can be divided into three groups categorized based on the amount of pressure.

The experimental results for the test at the $45^{\circ}$ angle with $3 \mathrm{~kg}$ fiber, in get rotation on the screw shaft of $84.5 \mathrm{rpm}$, then cutting on the briquette sample produced with a length of $40 \mathrm{~mm}$. Specimens that have been cut off are done by using an oven at $250{ }^{\circ} \mathrm{C}$ for 3.5 hours to reduce the moisture content and then specimens are burned to ashes, The length of time the burning of the specimen to ash is obtained for 65 minutes. The same way and process as the above experiment for testing at the mold angle $55^{\circ}$ and $65^{\circ}$ can be seen and concluded on the Table 1 .

Table 1. The angle effect on the length of time of specimen burning

\begin{tabular}{c|c}
\hline Angle $\left(^{\circ}\right)$ & Time (minutes) \\
\hline 45 & 65 \\
55 & 63 \\
65 & 62 \\
\hline
\end{tabular}

Fig. 4 is a sample of briquettes resulting from the printing process with a briquette machine as shown in Fig. 2. Each sample is made of three pieces to obtain more data and analysis. Fig. 3(b) is a briquette burning test to determine the quality of combustion produced. The analysis shows that the effect of the angle of the mold on the duration of combustion shows the difference in the time value that is not significant between the angles $45^{\circ}, 55^{\circ}$ and $65^{\circ}$.

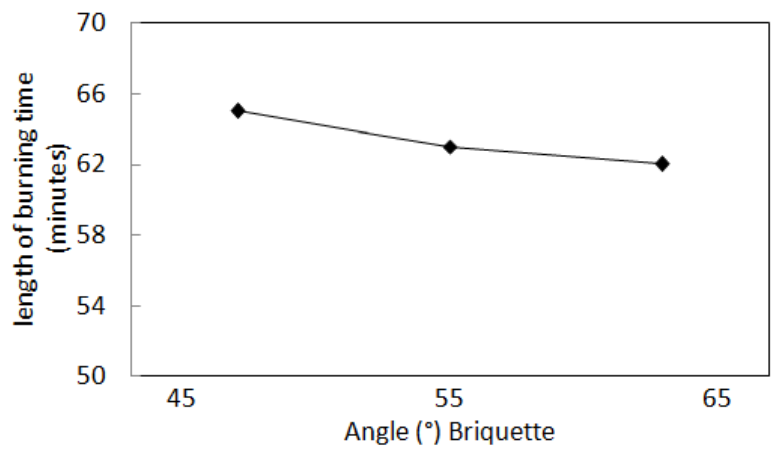

Fig. 4. Graph effect of angle vs length of burning time
The Graph Fig. 5 shows that a specimen using $45^{\circ}$ angle of mold produces a briquette burning time of $65^{\circ}$ minutes, while at $65^{\circ}$ angles the resulting combustion time is only 62 minutes. Seen that the time difference is only 1 to 2 minutes. This is because at the mold angle $45^{\circ}$ the resulting briquettes are denser than angles $55^{\circ}$ and $65^{\circ}$. The conclusive analysis of this study is that the more dense the briquettes affect the density and physical properties.
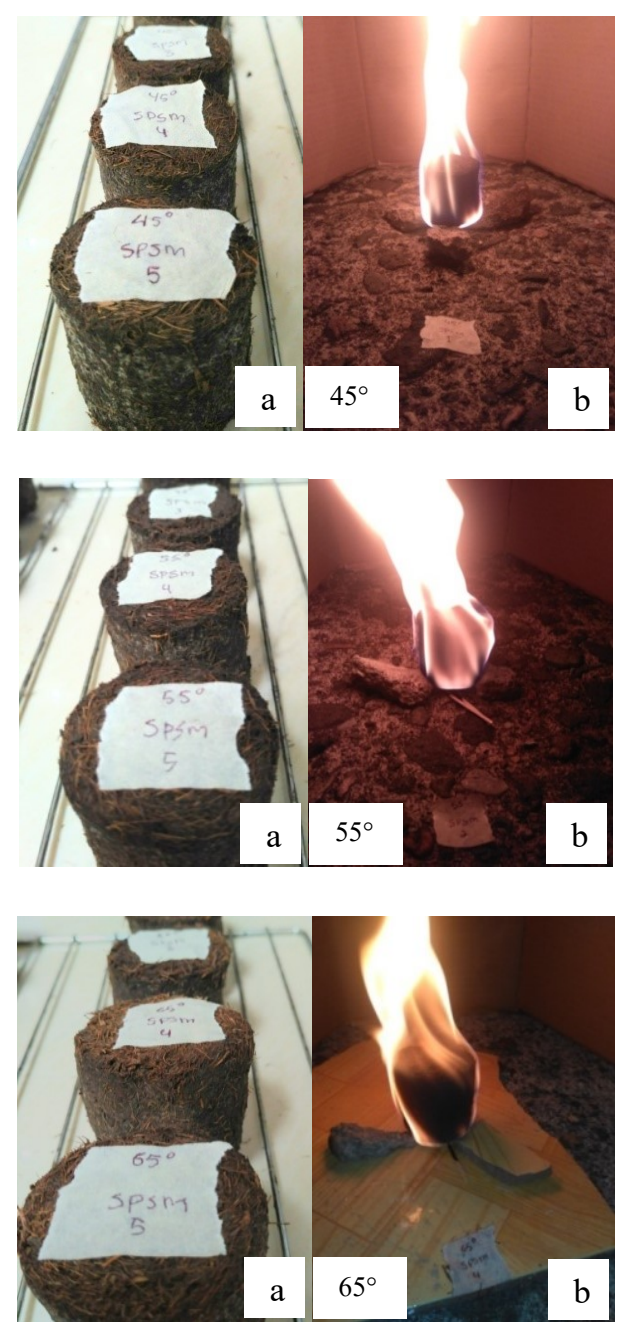

Fig. 5. Samples of $45^{\circ}, 55^{\circ}$ and $65^{\circ}$ angle briquettes (a) and the combustion (b)

Fig. 6 Graph shows that rotation on the highest screw shaft at an angle of $65^{\circ}$ with a rotation value of $90.6 \mathrm{rpm}$, while the lowest rotation is produced at an angle of $45^{\circ}$ with a value rotation of $84.5 \mathrm{rpm}$. This indicates that the greater the angle of mold briquette feeding the rotation of the screw axis will be higher and the smaller the angle of mold then the pivot rotation will be lower, this will cause the shaft load to rotate the screw will be greater due to the influence of angle. Difference of rotation value (rpm) between angle $55^{\circ}$ and $65^{\circ}$ shows no significant difference. 


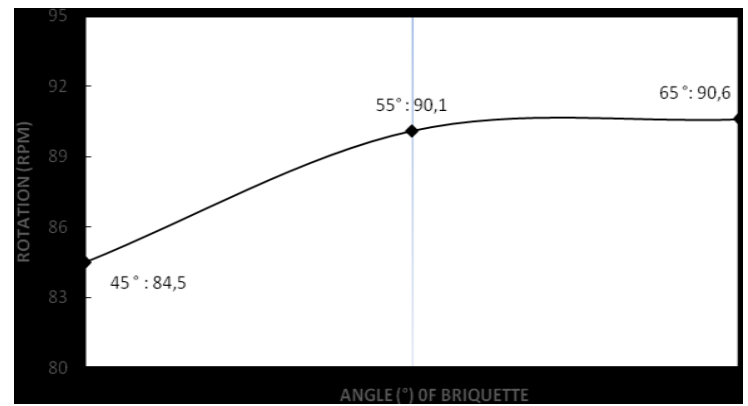

Fig. 6. Graph effect of angle vs rotation of screw shaft

\section{Conclusion}

1. Effect of the angle of the mold on the duration of combustion shows the difference in the time value that is not significant between the angles $45^{\circ}, 55^{\circ}$ and $65^{\circ}$.

2. The rotation of the screw shaft slows down at an angle of $45^{\circ}$ with a round of $84.5 \mathrm{rpm}$, while the rotation of the shaft has increased in rotation at $65^{\circ}$ angle with rotation of $90.6 \mathrm{rpm}$.

3. Differences in the cone angle affect the value of the burning time of the specimen and the rotation of the screw shaft so that it affects the engine performance

\section{References}

[1] N. Handra, IOP Conference Series: Earth and Environmental Science Effect of Binder on Combustion Quality on EFB Effect of Binder on Combustion Quality on EFB Bio-briquettes, (2017).

[2] N. Handra and A. Kasim, Pengaruh Ukuran Partikel Bio-briket TKKS terhadap Nilai Kalor Effect of Particles Size on EFB Bio-briquettes of CalorificValue, vol. 7, no. 1, (2017).

[3] K. H. Khor, K. O. Lim, Z. a Zainal, P. Pinang, and N. Tebal, "Characterization of Bio-Oil: A By-Product from Slow Pyrolysis of Oil Palm Empty Fruit Bunches School of Physics, School of Mechanical Engineering , Engineering Campus," Am. J. Appl. Sci., vol. 6, no. 9, pp. 1647-1652, (2009).

[4] T. Deac, V. Ros, F. Mariasiu, M. Deac, and B. Muncii, "The influence of the sawdust briquettes geometric parameters on the conversion efficiency," vol. 43, no. 103, pp. 306-311, (2011).

[5] P. Wilaipon, The Effects of Briquetting Pressure on Banana-Peel Briquette and the Banana Waste in Northern Thailand., American Journal of Applied Sciences 6 (1): 167-171, (2009).

[6] R.M. Singh, H.J. Kim, Mitsushi. K, and S. Toran, Briquettes-an Alternative Fuel for Sustainable Development, Nepal Journal of Science and Technology 10: pp: 121-127, (2009) 